Research Article

\title{
Diurnal Variations in Summer Precipitation over the Yellow River Basin
}

\author{
Yang Zhao $\mathbb{D},{ }^{1,2}$ Minzhong Wang $\mathbb{D}^{3},{ }^{3}$ Jiao Li $\mathbb{D},{ }^{4}$ Xiaojun Yang, ${ }^{5}$ Nan Zhang, ${ }^{5}$ \\ and Hong Chen ${ }^{5}$ \\ ${ }^{1}$ State Key Laboratory of Severe Weather, Chinese Academy of Meteorological Sciences, Beijing 100081, China \\ ${ }^{2}$ Nanjing University of Information Science \& Technology, Nanjing, 210044, China \\ ${ }^{3}$ Institute of Desert Meteorology, China Meteorological Administration, Urumqi 830002, China \\ ${ }^{4}$ Henan Province Climate Center, Zhengzhou 450003, China \\ ${ }^{5}$ Tianjin Meteorological Observatory, Tianjin 300074, China \\ Correspondence should be addressed to Minzhong Wang; wangmz@idm.cn and Jiao Li; lijiao0606@126.com
}

Received 8 August 2018; Revised 18 December 2018; Accepted 22 January 2019; Published 27 February 2019

Academic Editor: Efthymios I. Nikolopoulos

Copyright (C) 2019 Yang Zhao et al. This is an open access article distributed under the Creative Commons Attribution License, which permits unrestricted use, distribution, and reproduction in any medium, provided the original work is properly cited.

\begin{abstract}
The diurnal variations in summer precipitation over the Yellow River Basin (YRB) are investigated based on the National Centers for Environmental Prediction reanalysis dataset and hourly precipitation data from 481 gauge stations over the YRB during the time period 1981-2013. Three stair steps are identified to represent the upper, middle, and lower reaches of the YRB due to complex topography elevations over the different subregions of the YRB. The summer diurnal precipitation over the YRB shows significant spatial and temporal variations. The diurnal peaks in precipitation over the upper and middle reaches of the YRB occur in the evening and late afternoon, respectively. By contrast, double peaks in diurnal precipitation occur in the early morning and late afternoon over the lower reaches of the YRB. The diurnal peaks in summer precipitation along the YRB have an eastward transition, suggested to be associated with the westerlies transporting water vapor. Differing from the increasing tendency of summer hourly precipitation from west to east across the YRB with topography elevations decreased, a distinct reduction in hourly precipitation is observed over the transition region between the first and second stair steps in the YRB. Further analysis attributes this phenomenon to the regional descending airflow induced by the steep terrain along the slope of the Tibetan Plateau (TP).
\end{abstract}

\section{Introduction}

As one of the most fundamental characteristics of precipitation regime, the diurnal variations in precipitation are known to be a response to both the evolution of synoptic and climatic systems and local forcing [1-5]. Diurnal variations in precipitation are important in weather and climate on both local and global scales, which have strong implications for the hydrological cycle and agriculture [6]. The diurnal variations in precipitation have received much attention from meteorologists. Wallace [7] analyzed the amplitude and phase of different types of diurnal precipitation over the United States and showed a large-scale geographical consistency in these diurnal variations. Dai [8] investigated the diurnal variations in the frequency of different types of precipitation on the global scale. Hirose and Nakamura [9] referred the diurnal features in precipitation systems to their size, with small-scale systems often occurring in the early afternoon over land masses and large systems occurring in the evening. A peak in nocturnal precipitation is observed to be prominent impacted by terrains such as the Tibetan Plateau (TP) and its surrounding areas $[10,11]$.

In China mainland, the diurnal variations in summer precipitation have been widely reported. Yuan et al. [12] proposed some different regimes of diurnal precipitation in summer over subtropical East Asia, with influences from large-scale mountain-valley, land-sea, and convective systems. Yu et al. [1] confirmed that summer precipitation in China shows large diurnal variations with related regional features. Two diurnal peaks in summer precipitation were 
observed in the area between the Yangtze River and the Yellow River, with one peak in the early morning and the other in the late afternoon. Yu et al. [13] found a close relationship between the duration of rainfall and the diurnal variations in warm season precipitation over central and eastern China. A distinct feature of summer precipitation over eastern China is the eastward phase delay in diurnal precipitation. A similar phenomenon has been observed over the U.S. Great Plains, which several researchers have attributed to the eastward propagation of convection systems from the upstream Rockies Mountains to the U.S. Great Plains $[14,15]$. The local peak phase of diurnal precipitation usually propagates eastward from the eastern edge of the TP to eastern China, with one dominant diurnal precipitation peak in the mid-afternoon (with maximum solar heating), while a secondary propagating maximum, as a continuation of the signal from the TP and the Sichuan Basin, occurs at around midnight on the second day [16]. Chen et al. [17] attributed the eastward phase transition of long-duration rain along the Yangtze River to the diurnal clockwise rotation of anomalous low-level winds and advection from the TP. Jin et al. [18] suggested that the prominent eastward timing delay in the diurnal precipitation peak over the Sichuan Basin was caused by the TP and low-level winds. The eastward phase transition of diurnal precipitation in summer over eastern China is probably associated with terrains and low-level winds.

The Yellow River Basin (YRB) (33.5-41.5 $\left.\mathrm{N}, 96-119^{\circ} \mathrm{E}\right)$, regarded as the "Mother River of China," is the second longest river in China and the fifth largest river in the world and directly feeds a population of 107 million people [19, 20]. The Yellow River crosses a number of complex terrains, rising on the TP, flowing through the Loess Plateau and North China Plain, before discharging into the Bohai Sea. Anomalous summer precipitation over the YRB causes frequent droughts and floods, resulting in the displacement of millions of residents, devastated crops, and soil erosion over large areas of land [21]. Bao et al. [16] suggested that research on the diurnal variations in summer precipitation to the east of the TP, including the middle to lower reaches of the YRB, would improve the skill of regional precipitation forecasts.

The diurnal cycle of precipitation in Shandong, in the lower reaches of the YRB, has two peaks, one in the early morning and one in the afternoon [22]. He and Zhang [6] suggested that the diurnal peaks in warm season precipitation along the middle to lower reaches of the YRB have an eastward propagation and both the mountain-plain solenoid circulation and low-level southwesterly jet are responsible for the nocturnal peak in precipitation over the North China Plain. The features of diurnal precipitation in summer over some subregions of the YRB have been recognized, while the regional differences in diurnal precipitation across the entire YRB in summer remain unclear. As a result of the complex terrains over the upper, middle, and lower reaches of the YRB, the variations of diurnal precipitation in summer over the transition areas of different subregions of the YRB require further investigation.

The aim of this study was to investigate the general features of diurnal precipitation over the YRB in summer and to analyze their regional differences. The diurnal precipitation variations in the transition areas of different elevation terrains across the YRB and their possible causes were considered. This paper is organized as follows. Section 2 introduces the data and methods. Section 3.1 identifies the spatial distribution of the hourly mean precipitation in summer over the YRB and the climatological water vapor transport pathways for summer precipitation in situ. Section 3.2 explores the regional differences in summer diurnal precipitation over the YRB. The variation in the summer diurnal precipitation in the transition areas of different elevation terrains over the YRB is given in Section 3.3. Section 4 presents our discussion and conclusions.

\section{Data and Methods}

2.1. Data. The Yellow River is about $5464 \mathrm{~km}$ long with a drainage area of $752,400 \mathrm{~km}^{2}$ [23]. The YRB is located in the arid and semiarid regions of China (Figure 1, red box), which are strongly influenced by the East Asian summer monsoon (EASM) and modulated by westerlies in Northern Hemisphere [24-26]. Precipitation amount in the JuneJuly-August months accounts for a large portion of the total annual precipitation amounts over the YRB (Figure 1), and then summer refers to June-July-August in this study [20, 25, 27].

From the source to the river mouth, the YRB experiences three-section different topography elevations [28]. The first section, with an altitude $>2000 \mathrm{~m}$, represents the upper reaches of the YRB and the northeastern TP. The second section, with an altitude of $1000-2000 \mathrm{~m}$, is defined as the middle reaches of the YRB. The third section, with altitudes $<1000 \mathrm{~m}$, is mainly located on the plains of northern China. Figure 2 is a topographical map of the YRB showing the locations of 481 meteorological stations and subregions. To facilitate our study and provide a brief overview of the climate of the subregion, we used three stair steps to denote the three sections of the YRB with different topographic elevations. The three stair steps represent the upper, middle, and lower reaches of the YRB.

The observational dataset used in this study consists of hourly precipitation in the time period 1981-2013 at 481 surface meteorological observation stations over the YRB obtained from the National Meteorological Information Center (NMIC) of the China Meteorological Administration (http://data.cma.cn). There are 31, 202, and 248 rain gauge stations in areas $\mathrm{A}, \mathrm{B}$, and $\mathrm{C}$ of the $\mathrm{YRB}$, respectively; the locations of these stations are shown in Figure 2(a). The long-term monthly mean series of regional averaged precipitation acquired from the daily precipitation data at the same 481 stations over the YRB in summer from 1961 to 2010 provided by the NMIC were calculated to help determine the water vapor transport pathways of summer precipitation over the YRB. These rain stations are evenly distributed over the entire YRB, except from stations over the northern TP and the border between Inner Mongolia and Mongolia. Data from these stations have undergone strictly quality control procedures by the NMIC. The quality control consists of two steps: an extreme check and a 


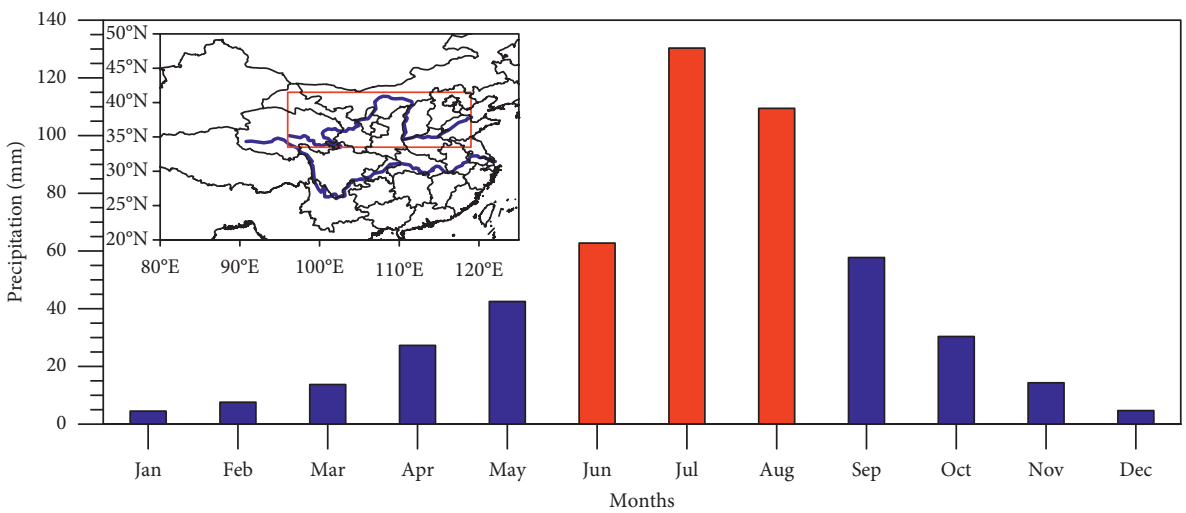

FIgURE 1: Variation in the monthly mean precipitation (units: mm) over the Yellow River Basin (YRB) from 1961 to 2010 . The red bars indicate the summer months studied in this research. The inset is a map of China, with the red box showing the location of the YRB $\left(33.5-41.5^{\circ} \mathrm{N} 96-119^{\circ} \mathrm{E}\right)$. The two blue lines denote the Yellow River and the Yangtze River, respectively.

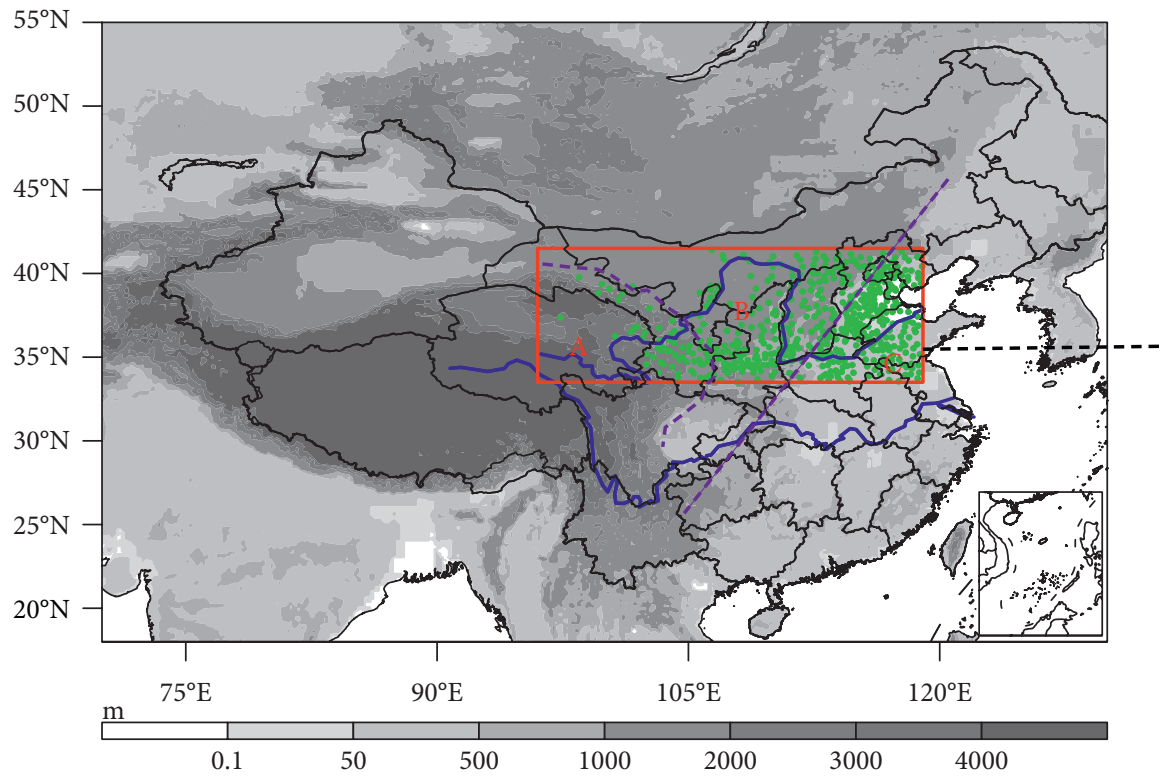

(a)

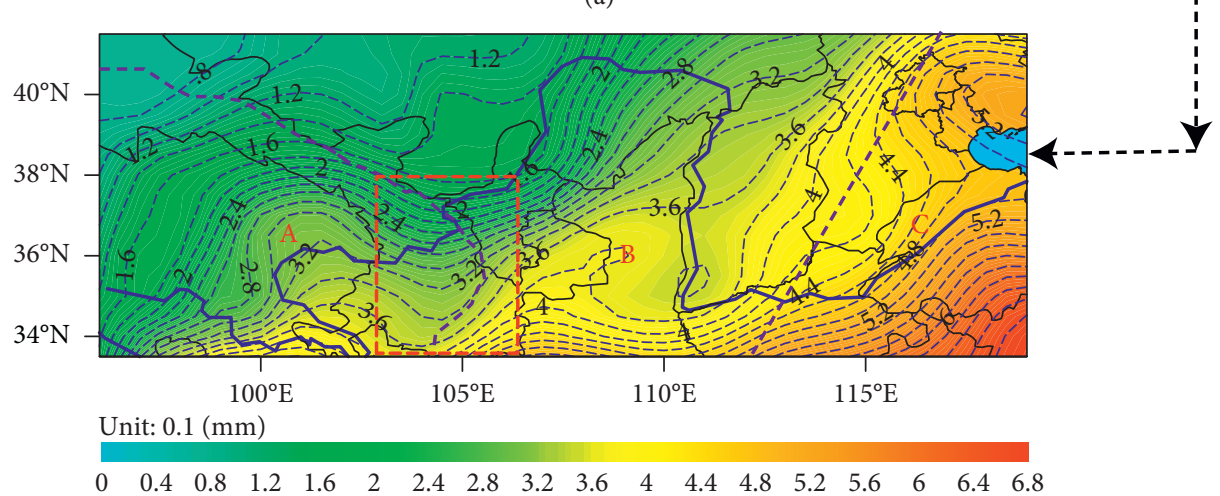

(b)

Figure 2: (a) Locations of 481 meteorological stations (green dots) in the YRB (red box). The solid blue line in the red box represents the Yellow River. The altitude of the large-scale topography is presented as a gray scale (units: $\mathrm{m}$ ). The purple dashed lines show the distribution of the three stair step topographic regions defined by elevation. Area A represents the upper reaches of the YRB, area B denotes the middle reaches of the YRB, and area C refers to the lower reaches of the YRB. The black box in the bottom right-hand corner shows the South China Sea islands. (b) Spatial distribution of the hourly mean precipitation (units: $0.1 \mathrm{~mm}$ ) across the YRB during the summer months from 1981 to 2013. The two purple dashed lines divide the three topographic regions defined by three stair steps. 
consistency check. The first step compares the real-time gauge records with the climatological extreme values (usually the maximum values of the daily precipitation series during a given month). Because the quality of the daily precipitation data is well controlled by the NMIC, all the hourly rain gauge data exceeding the monthly maximum daily precipitation in the same period are rejected. The second step is to check the temporal and spatial consistencies between candidate rain gauge records and those at the neighboring stations and times. The internal consistency is also used to identify erroneous data caused by incorrect units, reading, or data coding [1,29-31]. All the data meet the strict quality control standards required by the Rules on Ground Surface Meteorological Observations [32]. The local solar time (LST) was used in this study.

The monthly mean wind and specific humidity fields with a horizontal resolution of $2.5^{\circ} \times 2.5^{\circ}$ during the time period 1961-2010 acquired from the National Centers for Environmental Prediction (NCEP) (https://www.esrl. noaa.gov/psd/data/gridded/data.ncep.reanalysis.derived.html) were used to determine the water vapor transport pathways of summer precipitation over the YRB. The 6-hourly wind fields during the time period 2000-2014 from the NCEP Final Operational Global Analysis datasets were used to analyze the regional circulation pattern over the transition areas of different elevation terrains along the YRB. The dataset with a horizontal resolution of $1^{\circ} \times 1^{\circ}$ begins in 1999 (https://rda.ucar.edu/datasets/ds083.2/).

\subsection{Methodological Analysis}

2.2.1. Calculation of the Integrated Column Water Vapor Flux. The YRB lies in the northern part of the EASM regime, where the water resources system is sensitive to climate change. Water vapor transport plays a vital part in precipitation over the YRB $[33,34]$. Research into the relationship between water vapor transport and the diurnal variations of summer precipitation over the YRB is negligible. The zonal and meridional components of the integrated column water vapor flux are defined as follows [35]:

$$
\begin{aligned}
& q u(x, y, t)=\frac{1}{g} \int_{p_{\mathrm{s}}}^{p_{\mathrm{T}}} q u(x, y, p, t) d p, \\
& q v(x, y, t)=\frac{1}{g} \int_{p_{\mathrm{s}}}^{p_{\mathrm{T}}} q v(x, y, p, t) d p,
\end{aligned}
$$

where $x$ is the zonal field, $y$ is the longitudinal field, $p$ represents the vertical level, and $t$ represents time. $g$ is the acceleration due to gravity, $q$ is the specific humidity, and $u$ and $v$ are the zonal and meridional winds, respectively. $p_{\mathrm{s}}$ is the pressure at the sea surface, and $p_{\mathrm{T}}$ is the pressure at the top of the atmosphere.

2.2.2. Correlation Vectors between Regional Averaged Summer Precipitation over the YRB and the Integrated Column Water Vapor Flux. The monthly mean precipitation in summer acquired from the daily precipitation gauge data was calculated for each station and then averaged across the
YRB to derive the regional mean. The correlation between the regional averaged summer precipitation over the YRB and the integrated column water vapor flux was then calculated [36]:

$$
\begin{aligned}
& R_{\mathrm{u}}=\frac{1}{(n-1)} \cdot \frac{\sum_{i=1}^{n}\left(x_{k i}-\overline{x_{k}}\right)\left(q u_{l i}-\overline{q u_{l}}\right)}{\left(x_{k s t d} * q u_{l s t d}\right)}, \\
& R_{\mathrm{v}}=\frac{1}{(n-1)} \cdot \frac{\sum_{i=1}^{n}\left(x_{k i}-\overline{x_{k}}\right)\left(q v_{l i}-\overline{q v_{l}}\right)}{\left(x_{k s t d} * q v_{l s t d}\right)}
\end{aligned}
$$

where $R_{\mathrm{u}}$ and $R_{\mathrm{v}}$ represent the correlation coefficients between the regional averaged summer precipitation and the water vapor flux in the zonal and meridional components $q u$ and $q v$, respectively, $x_{k i}$ is regional averaged summer precipitation, $n$ is the number of years. $\overline{x_{k}}$ is the multiyear mean of regional averaged summer precipitation, $\overline{q u_{l}}$ and $\overline{q v_{l}}$ are the multiyear mean of the zonal and meridional integrated column water vapor fluxes, respectively. $q u_{l i}$ and $q v_{l i}$ are the zonal and meridional integrated column water vapor fluxes at the order year of $i$, respectively. $x_{k s t d}, q u_{l s t d}$, and $q v_{l s t d}$ are the standard deviations of the regional averaged summer precipitation and the zonal and meridional water vapor fluxes, respectively.

The equation of the water vapor correlation vector is shown as follows $[37,38]$ :

$$
R(x, y)=R_{\mathrm{u}}(x, y)+R_{\mathrm{v}}(x, y),
$$

where $R(x, y)$ is the correlation vector between the regional averaged summer precipitation and the water vapor flux. $R_{\mathrm{u}}(x, y)$ and $R_{\mathrm{v}}(x, y)$ are the zonal and meridional components of the correlation vector, respectively.

\section{Results}

3.1. Basic Features of Hourly Mean Precipitation over the YRB in Summer. The hourly mean precipitation along the YRB in summer during the time period 1981-2013 was calculated (Figure 2(b)). The hourly mean precipitation in the upper reaches of the YRB (area A) ranged from about 0.1 to $0.3 \mathrm{~mm}$. In the middle reaches of the YRB (area B), the hourly precipitation varied from about 0.3 to $0.4 \mathrm{~mm}$. In the lower reaches of the YRB (area C), the hourly mean precipitation increased to $>0.4 \mathrm{~mm}$, with a maximum of about $0.6 \mathrm{~mm}$ over the southeastern lower reaches of the YRB. In general, the hourly mean precipitation increased from west to east across the YRB. The hourly mean precipitation at higher elevations was less than that over the plains. There was a clear difference in the hourly mean precipitation between two adjacent subregions from west to east in the YRB, as demarcated by the dashed purple lines in Figure 2(b).

Water vapor transport cannot be ignored when studying precipitation over the YRB because the basin lies in the summer monsoon regime $[33,34]$. The climatological water vapor transport pathways for the Loess Plateau, located in the middle reaches of the YRB, include the northward pathway from the Indian Ocean and the EASM, and the eastward pathway via westerlies [39]. Ma et al. [40] 
concluded that four main climate systems covering the Indian monsoon, mid-latitude westerlies, the East Asian monsoon system, and local moisture recycling play vital roles in controlling water vapor transport to the upper reaches of the YRB. Local rainstorms over northwest China primarily derive their water vapor from westerlies [41]. The water vapor transport pathways of summer precipitation over the YRB are worthy to be explored. Figure 3 shows the correlation fields between summer precipitation over the YRB and the simultaneous column-integrated water vapor transport during the time period 1961-2010. A Lake Baikal trough accompanied by a distinct cyclonic water vapor flux vortex is located on the northern boundary of the TP, whereas the eastern boundary of the TP is associated with an anticyclonic water vapor flux vortex. Two dominant water vapor transport pathways over the YRB are closely related to westerlies and the southerly monsoon flow, respectively (Figure 3, green arrows). The major sources of the two water vapor transport pathways include westerlies, the tropical Indian Ocean, and the western Pacific Ocean, similar to the results of previous studies $[39,41]$. This section underlies the spatial features of the hourly mean precipitation over the three stair steps of the YRB in summer and the climatological water vapor transport pathways of summer precipitation over the YRB, including the eastward pathway via westerlies and the northward monsoon flow pathway from the tropical oceans.

\subsection{Regional Differences in Diurnal Precipitation over the} Three Stair Steps of the YRB in Summer. The general spatial features of the hourly mean summer precipitation over the YRB have been acknowledged. To recognize the diurnal variations in the summer precipitation in situ, Figure 4 shows the diurnal variations in the 1981-2013 mean summer precipitation averaged over the three stair steps of the YRB. The diurnal precipitation in the upper reaches of the YRB (area A) shows a distinct pattern, with the maximum precipitation amount in the evening at 2100 LST and the minimum in the afternoon at 1400 LST (Figure 4(a)). In the middle reaches of the YRB (area B), the minimum hourly precipitation occurs at noon and the maximum in the late afternoon at 1700 LST (Figure 4(b)). In the lower reaches of the YRB (area C), the minimum hourly precipitation also occurs at noon, but there are two peaks: one in the early morning at about 0200 or 0400 LST and the other in the late afternoon at 1800 LST (Figure 4(c)).

The regional differences in the diurnal precipitation peaks over the three stair steps in summer deserve to be quantified. We divided each day into four periods: early morning (0200-0700 LST), late morning (0800-1300 LST), late afternoon (1400-1900 LST), and evening (2000-0100 LST). Figure 5 shows the percentages of stations with diurnal precipitation peaks occurring in these different time periods over each region in summer from 1981 to 2013. A total of $73.3 \%$ of the diurnal peaks in summer precipitation appear at 2000-0100 LST in area A, confirming previous study [42]. In area $\mathrm{B}, 70.79 \%$ of the diurnal precipitation peaks occur in the period 1400-1900 LST. Figure 4 shows that double

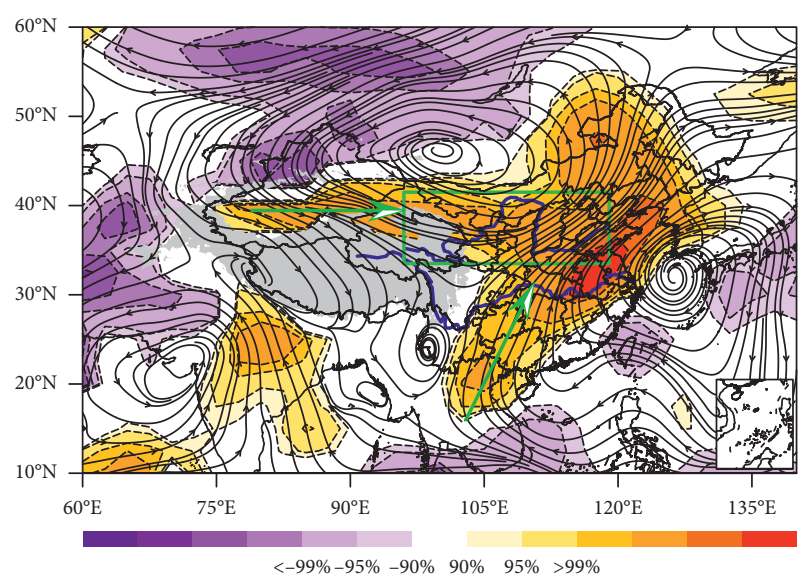

Figure 3: Correlation fields between the monthly mean precipitation (units: $\mathrm{mm}$ ) acquired from daily rain gauge data over the YRB and the monthly mean column-integrated water vapor transport (units: $\mathrm{g} \cdot \mathrm{m}^{-1} \cdot \mathrm{s}^{-1}$ ) in the summer months during the time period 1961-2010. The shaded colors represent the areas with correlations greater than the $90 \%$ confidence level. The gray area denotes the Tibetan Plateau (TP) terrain. The green box contains the entire YRB region. The black box in the bottom right-hand corner shows the South China Sea islands.

diurnal peaks occur in area C. One peak occurs at 0200-0700 LST and the other peak at 1400-1900 LST. The proportion of diurnal precipitation peaks during the later period (35.39\%) is greater than that during the earlier period $(33.74 \%)$. As the terrain elevation varies across the three stair steps of the YRB, the occurrence time of the diurnal precipitation maximum over the corresponding area also varies. Yu et al. [1] documented two comparable peaks of summer precipitation over central-eastern China between the Yangtze River and the Yellow River valley. Yu et al. [13] further claimed that precipitation events in the central and eastern plains of China lasting for longer than 6 hours tend to reach peak precipitation in the early morning, whereas precipitation events lasting less than 3 hours reach maximum hourly precipitation in the late afternoon. Zhuo et al. [22] reported two diurnal precipitation peaks in the early morning and afternoon over Shandong in the lower reaches of the YRB. Li et al. [43] identified two separate diurnal peaks in summer precipitation in Beijing, one in the late afternoon coming from short-duration rainfall and one in the early morning accumulated mostly by long-duration rainfall events. Wu et al. [44] suggested that summer precipitation in the YRB shows clear double diurnal peaks as the standard deviation of the subgrid topography decreases. Researches on the double peaks in diurnal precipitation suggest that the two peaks tend to occur on flat plains rather than on steep mountain ranges.

The occurrence time of the diurnal precipitation peaks shows distinct regional differences over the three stair steps of the YRB, although the detailed characteristics of the diurnal precipitation peaks from west to east in the YRB remain unknown. Figure 6 shows the spatial distribution of the most frequent hours for the summer diurnal precipitation peaks during the time period 1981-2013 at each 


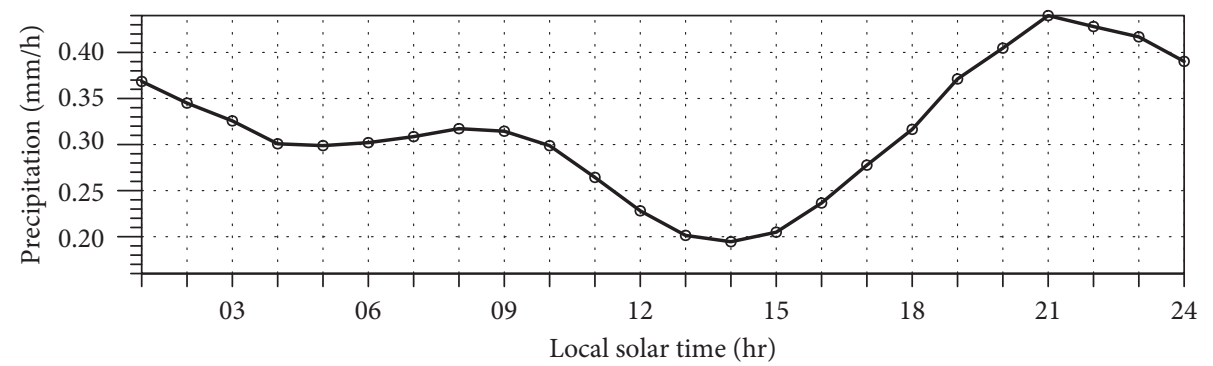

(a)

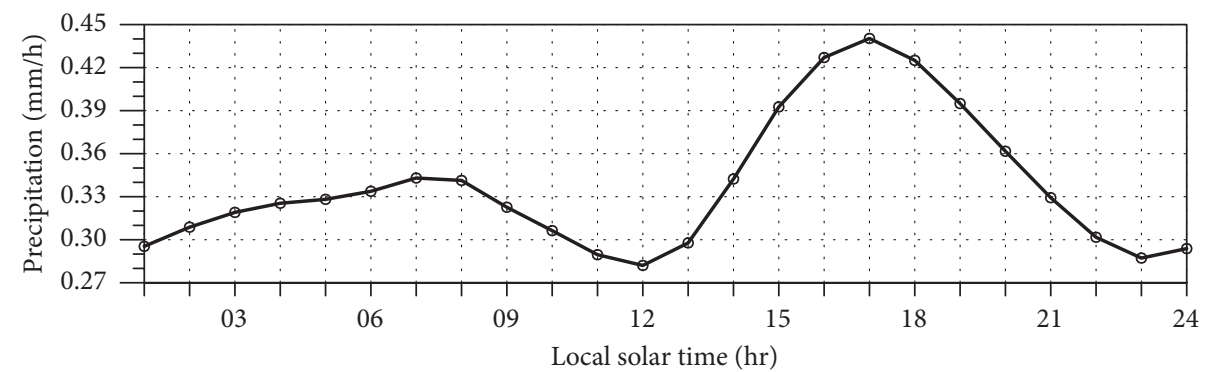

(b)

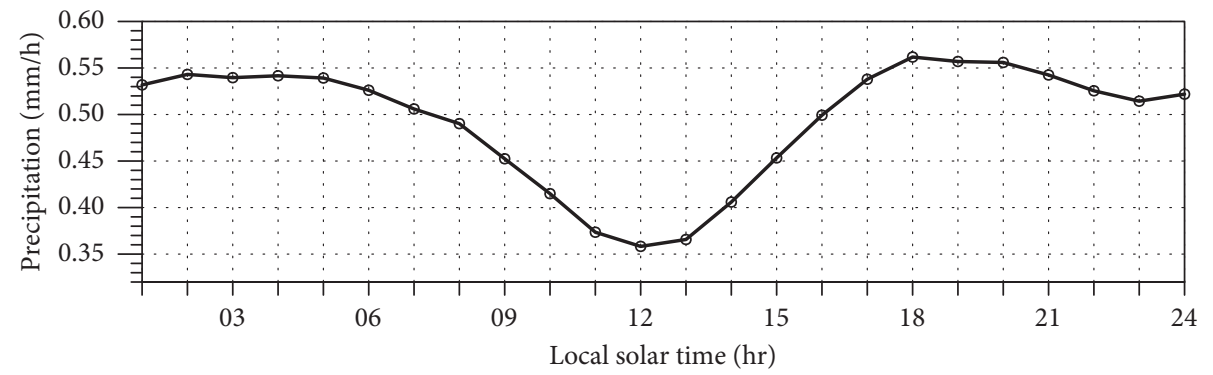

(c)

Figure 4: Diurnal variations in the 1981-2013 mean summer precipitation amount averaged over (a) area A, (b) area B, and (c) area C of the YRB. Note: the units of the vertical axis in each picture are $\mathrm{mm} /$ hour, and the horizontal axis shows the local solar time (LST).

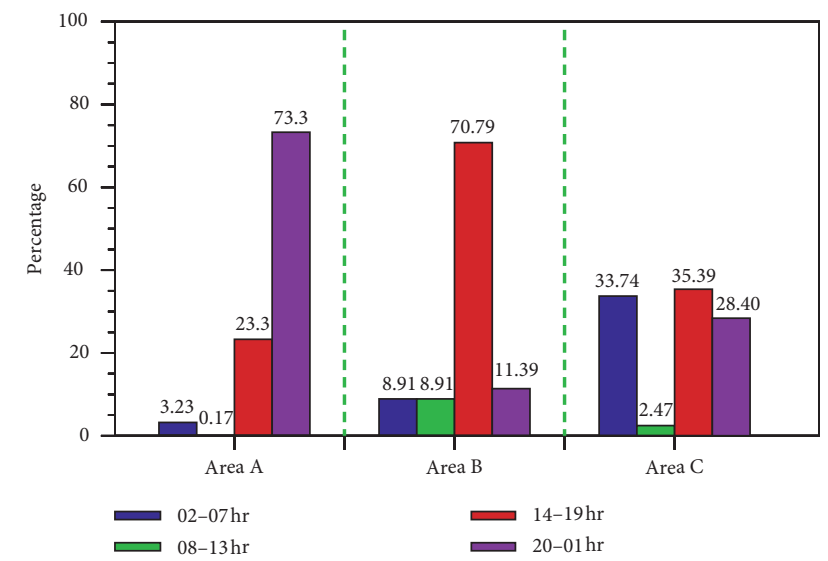

Figure 5: Percentages of stations with diurnal peaks in precipitation (units: $\mathrm{mm}$ ) occurring in different time periods (LST) over every region during the summer months. The blue bars represent the diurnal peaks in precipitation occurring between 0200 and 0700 LST, the green bars represent the diurnal peaks in precipitation occurring between 0800 and 1300 LST, the red bars represent the diurnal peaks in precipitation occurring between 1400 and 1900 LST, and the purple bars represent the diurnal peaks in precipitation occurring between 2000 and 0100 LST.

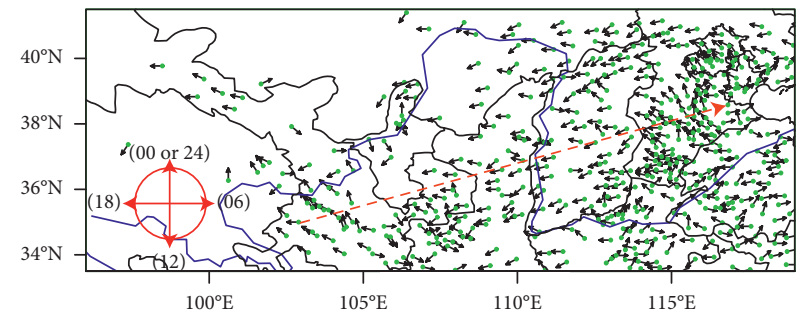

Figure 6: Spatial distribution of the most frequent hours of diurnal precipitation peaks in the summer months during the time period 1981-2013 at 481 stations across the YRB. The vectors denote the LST (see inset). The blue line denotes the Yellow River.

station over the three stair steps. The time of maximum diurnal precipitation is expressed by the arrow pointer on the $24 \mathrm{~h}$ clock. A clockwise evolution of the diurnal peak is observed from the evening in the upper reaches of the YRB, via the late afternoon over the middle reaches, and toward the early morning over the downstream reaches of the YRB (Figure 6, red dashed line). An eastward transition in the diurnal precipitation peak is evident across the YRB. The aforementioned research in this study identified that an 
eastward pathway via westerlies and a northward monsoon flow pathway from the tropical oceans provided the favorable water vapor background for summer precipitation over the YRB. Thus, the eastward transition of diurnal peaks in summer precipitation over the YRB is probably associated with westerlies.

3.3. Variation of Summer Diurnal Precipitation in the Transitional Areas of the Three Stair Steps over the YRB. As the terrain elevation decreases from the upper to the middlelower reaches of the YRB, the hourly precipitation increases significantly (Figure 7). However, the amount of precipitation suddenly decreases at about $104^{\circ} \mathrm{E}$ (Figure 7, dashed purple area labeled "A"). The same phenomenon is shown in Figure 2(b) (red dashed box). It is interesting that this area of decreased precipitation is located at a transition between the stair steps (an elevation of about $2000 \mathrm{~m}$ ), while the transition between the second and third stair steps at about $114^{\circ} \mathrm{E}$ does not show the same pattern (Figure 7, dashed purple area labeled "B").

To explain why the precipitation amount decreases in area $\mathrm{A}$, but increases in area $\mathrm{B}$, Figure 8 shows a vertical section of wind fields. At about $100-105^{\circ} \mathrm{E}$, the wind fields form a vertical anticyclonic circulation under the effect of the TP. The airflow rises near $100^{\circ} \mathrm{E}$ and then sinks at about $105^{\circ} \mathrm{E}$ (Figure 8, red circle). The transition area from the first to the second stair step is mainly controlled by the descending airflow near $104-105^{\circ} \mathrm{E}$ and local convection is restrained. However, the transition area from the second to the third stair step does not exhibit this circulation pattern; instead, the transition area performs relatively weak sinking airflow near $117^{\circ} \mathrm{E}$ (Figure 8, blue circle). As a consequence, the steep terrain exerts a more significant impact on diurnal precipitation in the transition zone between the first and second stair steps than the transition zone between the second and third stair steps.

\section{Discussion and Conclusions}

This paper primarily focuses on the diurnal variations in summer precipitation over the three stair steps of the YRB based on 481 rain gauge stations. Our conclusions are as follows.

The hourly mean precipitation in summer shows an increasing trend from the upper to the lower reaches of the YRB with decreasing topographic elevation. Two main pathways including an eastward pathway via westerlies and a northward pathway via the southerly monsoonal flows from tropical oceans provide the favorable water vapor background for summer precipitation over the YRB.

The peaks in diurnal precipitation occur at different times over the three stair steps in the YRB. The diurnal peak in precipitation occurs in the evening over the upstream region, but primarily occurs in the late afternoon over the middle reaches of the YRB. Double peaks in diurnal precipitation occur over the downstream reaches of the YRB, with the main peak in the late afternoon and the second peak in the early morning. An eastward transition of the diurnal

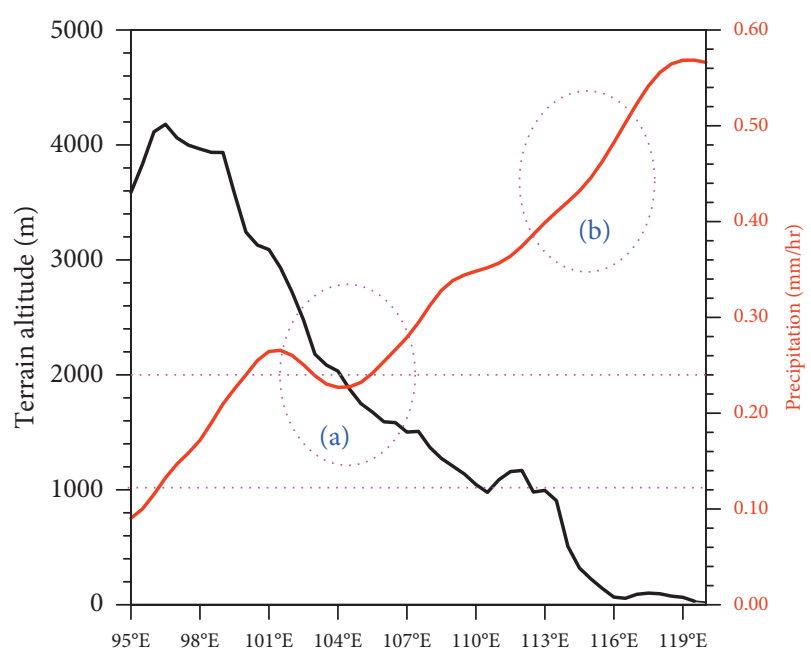

Figure 7: Zonal average $\left(33.5-42.5^{\circ} \mathrm{N}\right.$ terrain elevation (units: $\mathrm{m}$; left-hand $y$-axis) and the hourly precipitation rate (units: $\mathrm{mm} / \mathrm{hr}$; right-hand $y$-axis) along the YRB. The solid red line indicates the meridional distribution of the hourly precipitation rate, and the solid black line indicates the meridional distribution of the terrain height. Circle a denotes the transition region between the first and second stair steps of the YRB, and circle b denotes the transition region between the second and third stair steps of the YRB.

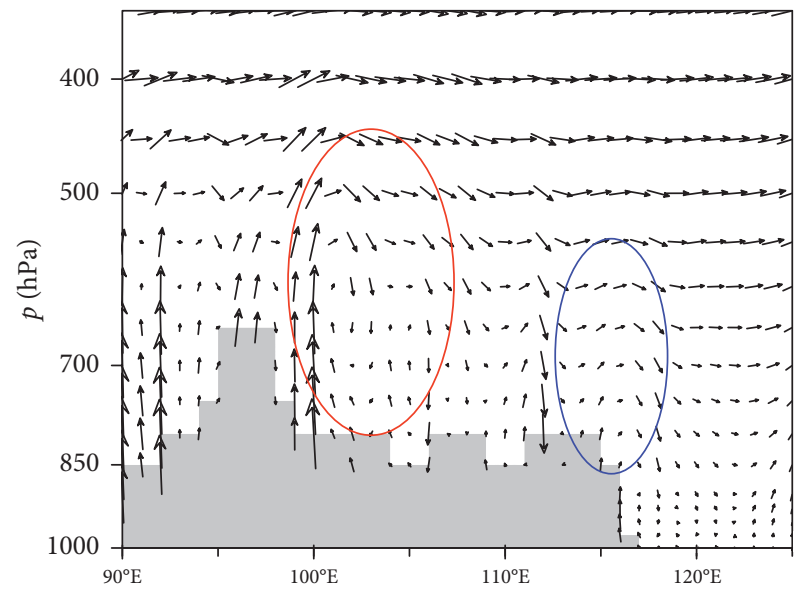

FIGURE 8: Daily mean zonal wind $u$ (units: $\mathrm{m} \cdot \mathrm{s}^{-1}$ ) and vertical velocity omega (unit: $\mathrm{hPa} \cdot \mathrm{s}^{-1}$ ) in the summer months from 2000 to 2014. The vertical section is in an east-west direction along the zonal average $33.5-42.5^{\circ} \mathrm{N}$. The red circle denotes the transition region between the first and second stair steps of the YRB, and the blue circle denotes the transition region between the second and third stair steps of the YRB. The gray shaded areas indicate the elevation of the terrain.

peaks in summer precipitation is evident across the YRB, indicating that this phenomenon may be associated with westerlies.

The hourly mean precipitation in summer increases from the western to eastern part of the YRB with the topography elevation decreased. An interesting feature is that the hourly mean precipitation experiences a distinct reduction from the first stair step to the second stair step. The regional descending airflow over the northeastern slope of 
the TP restricts convection over the transition area between the first stair step and the second stair step relative to the local circulation over the transition region between the second and third stair steps.

Wang et al. [45] reported that the mean annual precipitation is spatially heterogeneous, increasing from $368 \mathrm{~mm}$ in the upper reaches of the YRB to $530 \mathrm{~mm}$ in the middle reaches and $670 \mathrm{~mm}$ in the lower reaches. Our findings about the large-scale spatial distribution of the hourly mean precipitation over the YRB are similar to previously published results. Yu et al. [1] found that the zonal winds along the steep eastern slope of the TP induced diurnal variations in precipitation by triggering or suppressing deep convection. Wang et al. [46] showed that the local circulation arising from mountain-valley winds is responsible for the spatial differences in summer diurnal precipitation in Beijing. This study highlights a reduction in the hourly mean precipitation over the transition area between the first and second stair steps and attributes this distinct feature to the zonal descending airflow caused by steep terrain, which reflects the dominant effect of steep terrain on summer precipitation in the transition area of the YRB subregions. The variation in summer diurnal precipitation in the transition area between different topographic elevations may be invoked by the local circulation arising from steep mountain-valley winds.

Previous work has shown that the diurnal cycles in summer precipitation over eastern China show an eastward time delay in phase as a result of the thermally driven mountain-plain solenoids and water vapor transports carried by the accelerated nocturnal southwesterly winds [44]. The eastward transition of the diurnal precipitation peaks from the eastern edge of the TP to the downstream areas of the Yangtze River Valley is thought to be a result of the diurnal clockwise rotation of the accelerated nocturnal southwesterlies $[16,17]$. This study emphasizes the eastward transition of diurnal precipitation peak during the summer months from the upper to the middle-lower reaches of the YRB and links the eastward propagation to the westerlies that transport water vapor for summer precipitation over the YRB. The finding supplements previous research on the regional eastward transition of diurnal precipitation peaks. In addition to providing a favorable water vapor background for summer precipitation over the YRB, the westerlies have a crucial role in the variation in diurnal precipitation across the YRB, which may improve the parameterization in numerical weather forecasting models. This study has simply illustrated the diurnal precipitation variation across the YRB and associated it with westerlies; additional research is needed to understand the physical processes in this association.

Generally, research on the diurnal variations in summer precipitation over the YRB will improve short-term weather forecasting skills in situ, assist in the prevention of extreme hazards, help to develop a regional strategy for water resources management in the YRB, and provide insights into the links between climate change and the hydrological cycle.

The reasons for the diurnal precipitation peaks over different regions have been widely discussed. Surface solar heating could cause precipitation in the late afternoon [1]. The nocturnal precipitation peak over the eastern edge of the TP is attributed to the steep topography [42]. However, the mechanisms of the nocturnal and early morning precipitation are not limited by the terrain. Nocturnal convective systems are most vigorous after their development in the afternoon [47]. Lin et al. [48] reported that the nocturnal radiative cooling of clouds leads to a peak. The accumulation of moisture at night may also prompt nocturnal or early morning convection [49]. This study has shown the regional features of diurnal precipitation peaks across the YRB; their mechanisms over different regions need to be explored further.

Additionally, El Niño-Southern Oscillation (ENSO) is considered to be one of the most robust external forcing in the Earth's climate system. Some published researches demonstrated that the ENSO events would influence the regional diurnal variations in summer precipitation. Roy and Balling [50] reported that the overall patterns of diurnal precipitation over the Indian subcontinent were found to be robust against interannual variations, in the form of ENSO years. Li et al. [3] claimed that the early morning diurnal peak over the South China Sea is more significant during La Niña years than during El Niño years. Therefore, specific features and related mechanisms about the influences of ENSO events on the diurnal precipitation over the YRB need further investigation in the following research.

\section{Data Availability}

The data used to support the findings of this study are available from the corresponding author upon request.

\section{Conflicts of Interest}

The authors declare that they have no conflicts of interest.

\section{Acknowledgments}

The authors are grateful for access to the NCEP reanalysis dataset (https://www.esrl.noaa.gov/psd/data/gridded/data.ncep. reanalysis.derived.html), the NCEP FNL Operational Global Analysis dataset (https://rda.ucar.edu/datasets/ds083.2/), and data from the surface meteorological observation stations of the NMIC (China Meteorological Administration) (http:// www.nmic.cn/web/index.htm). The authors are grateful for support from the National Natural Science Foundation of China (41575008, 41775030), the Research on the Objective Prediction of Meteorological Elements in Tianjin Intelligent Network (2018041xxm01) and the Jiangsu Postgraduate Research and Innovation Program Project (KYCX17_0869).

\section{References}

[1] R. Yu, T. Zhou, A. Xiong, Y. Zhu, and J. Li, "Diurnal variations of summer precipitation over contiguous China," Geophysical Research Letters, vol. 34, no. 1, pp. 223-234, 2007.

[2] S. Yin, D. Chen, and Y. Xie, "Diurnal variations of precipitation during the warm season over China," International Journal of Climatology, vol. 29, no. 8, pp. 1154-1170, 2009. 
[3] W. Li, L. Cong, D. Wang, and T. Lei, "Diurnal variations of precipitation over the South China Sea," Meteorology \& Atmospheric Physics, vol. 109, no. 1-2, pp. 33-46, 2010.

[4] G. Kiely, J. D. Albertson, and M. B. Parlange, "Recent trends in diurnal variation of precipitation at Valentia on the west coast of Ireland," Journal of Hydrology, vol. 207, no. 3-4, pp. 270-279, 1998.

[5] M. D. Albright, E. E. Recker, R. J. Reed, and R. Dang, "The diurnal variation of deep convection and inferred precipitation in the central tropical pacific during JanuaryFebruary 1979," Monthly Weather Review, vol. 113, no. 10, pp. 1663-1680, 1985.

[6] H. He and F. Zhang, "Diurnal variations of warm-season precipitation over Northern China," Monthly Weather Review, vol. 138, no. 4, pp. 1017-1025, 2010.

[7] J. M. Wallace, "Diurnal variations in precipitation and thunderstorm frequency over the conterminous United States," Monthly Weather Review, vol. 103, no. 5, pp. 406-419, 1975.

[8] A. Dai, "Global precipitation and thunderstorm frequencies. Part I: seasonal and interannual variations," Journal of Climate, vol. 14, no. 6, pp. 1092-1111, 2001.

[9] M. Hirose and K. Nakamura, "Spatial and diurnal variation of precipitation systems over Asia observed by the TRMM Precipitation Radar," Journal of Geophysical Research, vol. 110, no. D5, p. 106, 2005.

[10] D. Ye and Y. Gao, The Meteorology of the Qinghai-Xizang (Tibet) Plateau, Science Press, Beijing, China, 1979, in Chinese.

[11] K. C. Chow and J. C. L. Chan, "Diurnal variations of circulation and precipitation in the vicinity of the Tibetan Plateau in early summer," Climate Dynamics, vol. 32, no. 1, pp. 55-73, 2009.

[12] W. Yuan, R. Yu, M. Zhang, W. Lin, H. Chen, and J. Li, "Regimes of diurnal variation of summer rainfall over subtropical east Asia," Journal of Climate, vol. 25, no. 9, pp. 3307-3320, 2012.

[13] R. Yu, Y. Xu, T. Zhou, and J. Li, "Relation between rainfall duration and diurnal variation in the warm season precipitation over central eastern China," Geophysical Research Letters, vol. 34, no. 13, pp. 173-180, 2007.

[14] X. Jiang, N. C. Lau, and S. A. Klein, "Role of eastward propagating convection systems in the diurnal cycle and seasonal mean of summertime rainfall over the U.S. Great Plains," Geophysical Research Letter, vol. 33, no. 19, 2006.

[15] H. Chen, T. Zhou, R. Yu, and J. Li, "Summer rain fall duration and its diurnal cycle over the US Great Plains," International Journal of Climatology, vol. 29, no. 10, pp. 1515-1519, 2009.

[16] X. Bao, F. Zhang, and J. Sun, "Diurnal variations of warmseason precipitation east of the Tibetan Plateau over China," Monthly Weather Review, vol. 139, no. 9, pp. 2790-2810, 2011.

[17] H. Chen, R. Yu, J. Li, W. Yuan, and T. Zhou, "Why nocturnal long-duration rainfall presents an eastward-delayed diurnal phase of rainfall down the Yangtze River valley," Journal of Climate, vol. 23, no. 4, pp. 905-917, 2010.

[18] X. Jin, T. Wu, and L. Li, "The quasi-stationary feature of nocturnal precipitation in the Sichuan Basin and the role of the Tibetan Plateau," Climate Dynamics, vol. 41, no. 3-4, pp. 977-994, 2013.

[19] T. R. McVicar, T. G. V. Niel, L. T. Li, M. F. Hutchinson, X. M. Mu, and Z. H. Liu, "Spatially distributing monthly reference evapotranspiration and pan evaporation considering topographic influences," Journal of Hydrology, vol. 338, no. 3-4, pp. 196-220, 2007.
[20] F. F. Zhao, Z. X. Xu, and J. X. Huang, "Long-term trend and abrupt change for major climate variables in the upper Yellow River Basin," Journal of Meteorological Research, vol. 21, no. 2, pp. 204-214, 2007.

[21] T. Gao and H. Wang, "Trends in precipitation extremes over the Yellow River basin in North China: changing properties and causes," Hydrological Processes, vol. 31, no. 13, pp. 2412-2428, 2017.

[22] H. Zhuo, P. Zhao, and T. Zhou, "Diurnal cycle of summer rainfall in Shandong of eastern China," International Journal of Climatology, vol. 34, no. 3, pp. 742-750, 2014.

[23] W. Wang, Q. Shao, T. Yang et al., "Changes in daily temperature and precipitation extremes in the Yellow River basin, China," Stochastic Environmental Research and Risk Assessment, vol. 27, no. 2, pp. 401-421, 2013.

[24] D. Chen and M. Lv, "Evaluating the influence of summer monsoon intensity on the runoff of the middle Yellow River basin," in Proceedings of AGU Fall Meeting, San Francisco, CA, USA, December 2012.

[25] J. Zhang, L. Li, D. Li, and W. Deng, "Summer droughts in the northern yellow river basin in association with recent arctic ice loss," International Journal of Climatology, vol. 35, no. 10, pp. 2849-2859, 2015.

[26] R. Jin, Z. Wu, and P. Zhang, “Tibetan Plateau capacitor effect during the summer preceding ENSO: from the yellow river climate perspective," Climate Dynamics, vol. 51, no. 24, pp. 57-71, 2018.

[27] C. Li, L. Wu, and P. Chang, "A far-reaching footprint of the tropical pacific meridional mode on the summer rainfall over the Yellow River Loop Valley," Journal of Climate, vol. 24, no. 10, pp. 2585-2598, 2011.

[28] D. Yang, C. Li, H. Hu et al., "Analysis of water resources variability in the Yellow River of China during the last half century using historical data," Water Resource Research, vol. 40, no. 6, p. 502, 2004.

[29] Z. H. Ren, P. Zhao, Q. Zhang, Z. F. Zhang, and L. J. Cao, "Quality control procedures for hourly precipitation data from automatic weather stations in China," Meteorological Monthly, vol. 36, no. 7, pp. 123-132, 2010, in Chinese.

[30] Q. Zhang, Y. Zhao, and S. Fan, "Development of hourly precipitation datasets for national meteorological stations in China," Torrential Rain \& Disasters, vol. 35, no. 2, pp. 182186, 2016, in Chinese.

[31] L. Zhong, Z. Zhang, L. Chen, J. Yang, and F. Zou, "Application of the Doppler weather radar in real-time quality control of hourly gauge precipitation in eastern China," Atmospheric Research, vol. 172-173, pp. 109-118, 2016.

[32] China Meteorological Administration, Rules of Ground Surface Meteorological Observations, Meteorological Press, Beijing, China, 2003, in Chinese.

[33] Y. Ding, Z. Wang, and Y. Sun, "Inter-decadal variation of the summer precipitation in east China and its association with decreasing Asian summer monsoon. Part I: observed evidences," International Journal of Climatology, vol. 28, no. 9, pp. 1139-1161, 2008.

[34] W. Wei, R. Zhang, M. Wen, X. Rong, and T. Li, "Impact of Indian summer monsoon on the south Asian high and its influence on summer rainfall over China," Climate Dynamics, vol. 43, no. 5-6, pp. 1257-1269, 2014.

[35] D. A. Howarth, "Seasonal variations in the vertically integrated water vapor transport fields over the southern hemisphere," Monthly Weather Review, vol. 111, no. 6, pp. 1259-1272, 1983.

[36] Y. Zhao, X. Xu, Z. Ruan, B. Chen, and F. Wang, "Precursory strong-signal characteristics of the convective clouds of the 
central Tibetan Plateau detected by radar echoes with respect to the evolutionary processes of an eastward-moving heavy rainstorm belt in the Yangtze River basin," Meteorology and Atmospheric Physics, 2018.

[37] X. D. Xu, X. Y. Shi, Y. Q. Wang, S. Q. Peng, and X. H. Shi, "Data analysis and numerical simulation of moisture source and transport associated with summer precipitation in the Yangtze River valley over China," Meteorology \& Atmospheric Physics, vol. 100, no. 1-4, pp. 217-231, 2008.

[38] Y. Zhao, X. Xu, B. Chen, and Y. Wang, "The upstream "strong signals" of the water vapor transport over the Tibetan Plateau during a heavy rainfall event in the Yangtze River basin," Advances in Atmospheric Sciences, vol. 33, no. 12, pp. 13431350, 2016.

[39] L. Yan, X. Liu, and Y. Zhou, "Variation in rainy season precipitation and associated water vapor transport over the Chinese Loess plateau during 1961-2012," Climate Research, vol. 58, no. 1, pp. 43-53, 2013.

[40] Y. Ma, M. Lu, H. Chen, M. Pan, and Y. Hong, “Atmospheric moisture transport versus precipitation across the Tibetan Plateau: a mini-review and current challenges," Atmospheric Research, vol. 209, pp. 50-58, 2018.

[41] L. Sun, B. Z. Shen, and B. Sui, "A study on water vapor transport and budget of heavy rain in Northeast China," Advances in Atmospheric Sciences, vol. 27, no. 6, pp. 13-1414, 2010.

[42] X. D. Liu, A. J. Bai, and C. H. Liu, "Diurnal variations of summertime precipitation over the Tibetan Plateau in relation to orographically-induced regional circulations," Environmental Research Letters, vol. 4, no. 4, pp. 940-941, 2009.

[43] J. Li, R. Yu, and J. Wang, "Diurnal variations of summer precipitation in Beijing," Science Bulletin, vol. 53, no. 12, pp. 1933-1936, 2008.

[44] Y. Wu, A. Huang, D. Huang et al., "Diurnal variations of summer precipitation over the regions east to Tibetan Plateau," Climate Dynamics, vol. 51, no. 11-12, pp. 4287-4307, 2018.

[45] H. Wang, Z. Yang, Y. Saito, J. P. Liu, X. Sun, and Y. Wang, "Stepwise decreases of the Huanghe (Yellow River) sediment load (1950-2005): impacts of climate change and human activities," Global and Planetary Change, vol. 57, no. 3-4, pp. 331-354, 2007.

[46] J. Wang, R. Zhang, and Y. Wang, "Areal differences in diurnal variations in summer precipitation over Beijing metropolitan region," Theoretical and Applied Climatology, vol. 110, no. 3, pp. 395-408, 2012.

[47] S. W. Nesbitt and E. J. Zipser, "The diurnal cycle of rainfall and convective intensity according to three years of TRMM measurements," Journal of Climate, vol. 16, no. 10, pp. 1456-1475, 2003.

[48] X. Lin, D. A. Randall, and L. D. Fowler, "Diurnal variability of the hydrologic cycle and radiative fluxes: comparisons between observations and a GCM," Journal of Climate, vol. 13, no. 23, pp. 4159-4179, 2000.

[49] H. Kubota and T. Nitta, "Diurnal variations of tropical convection observed during the toga-coare," Journal of the Meteorological Society of Japan, vol. 79, no. 3, pp. 815-830, 2001.

[50] S. S. Roy and R. C. Balling, "Diurnal variations in summer season precipitation in India," International Journal of Climatology, vol. 27, no. 7, pp. 969-976, 2007. 

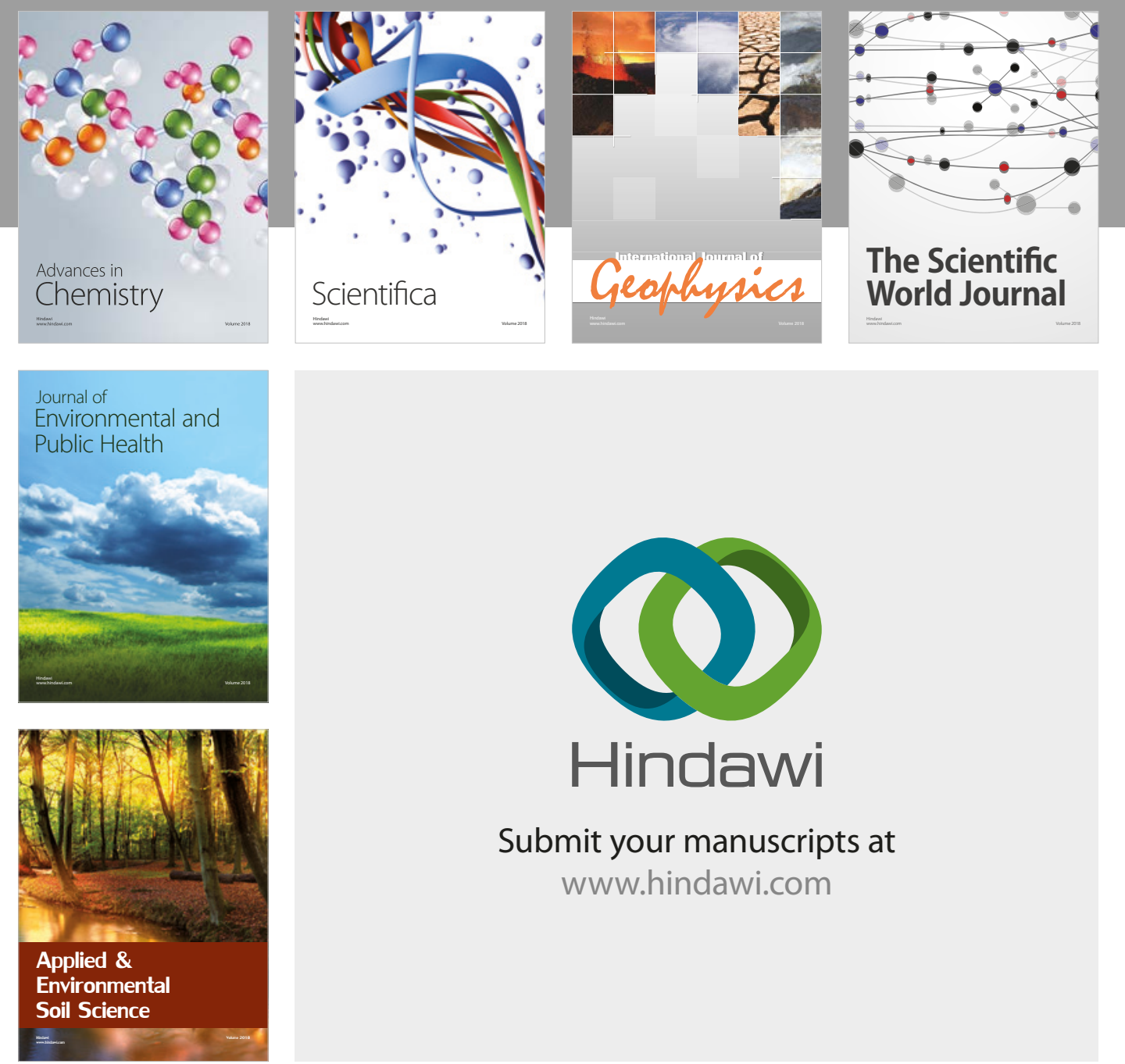

The Scientific

\section{World Journal}
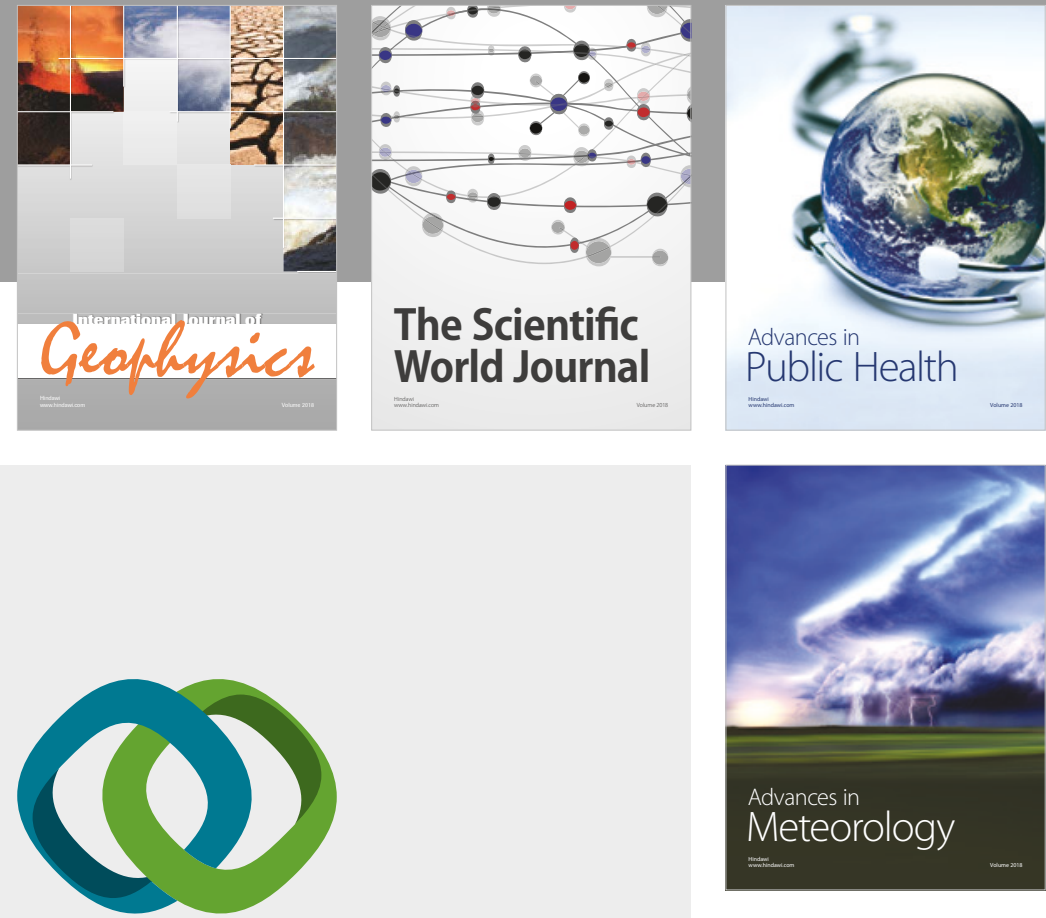

Advan

Public Health

\section{Hindawi}

Submit your manuscripts at

www.hindawi.com
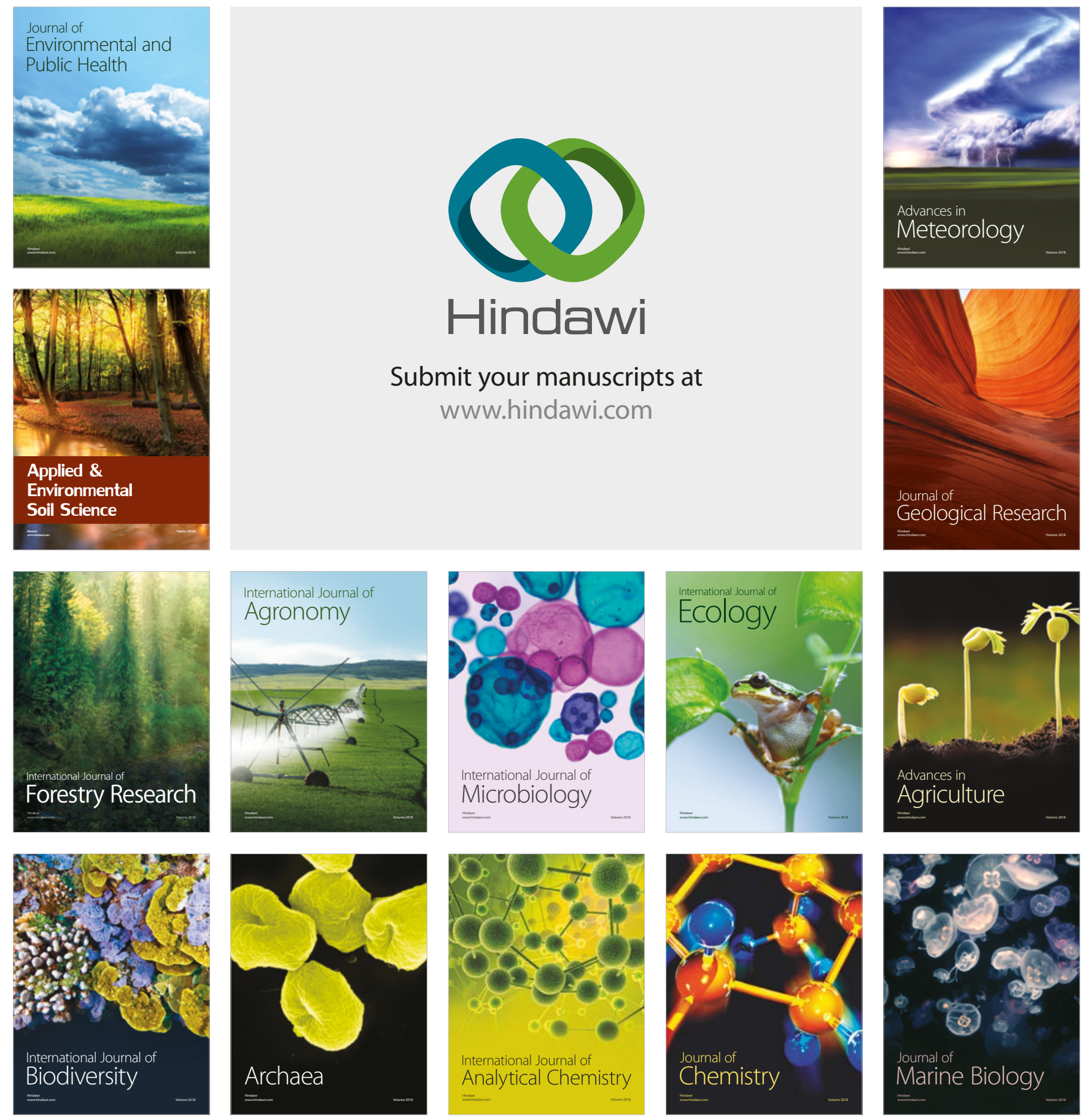